\title{
LONG-TERM VARIATIONS IN THE CORRELATION BETWEEN SOLAR ACTIVITY AND CLIMATE
}

\author{
Kirov B. ${ }^{1}$, Georgieva K. ${ }^{2}$ \\ ${ }^{1}$ Space Research and Technologies Institute - BAS, Sofia, Bulgaria \\ ${ }^{2}$ Climate, Atmosphere, and Water Research Institute-BAS, Sofia, Bulgaria

\section{ДОЛГОСРОЧНЫЕ ВАРИАЦИИ КОРРЕЛЯЦИИ МЕЖДУ СОЛНЕЧНОЙ АКТИВНОСТЬЮ И КЛИМАТОМ}

\author{
Киров Б. ${ }^{1}$, Георгиева К. ${ }^{2}$ \\ ${ }^{1}$ Институт Космических исследований и технологий - БАН, София, Болгария \\ ${ }^{2}$ Институт исследований климата, атмосферы и воды -БАН, София, Болгария
}

\begin{abstract}
После более чем 200 лет исследований воздействия солнечной активности на климат Земли вопрос продолжает быть дискусионным. Неопределенность вызвана тем, что некоторые авторы находят положительную корреляцию между изменениями приземной температуры воздуха и изменениями солнечной активности, в то время как другие устанавливают отрииателюную корреляичию. Мы показываем, что корреляция между солнечной активностью и температурой положительна, когда более активно северное солнечное полушарие и отрицательна, когда более активно южное полушарие. Далее, мы рассматриваем воздействие солнечной активности на крупномасштабные явления как Северноатлантическая осииллячия (NAO), которые определяют климат больших частей земной поверхности, и устанавливаем, что кроме от северно-южной ассиметрии солнечной активности, знак корреляции зависит и от соотнотения двух компонент солнечной активности - связанной с солнечными пятнами (с тороидальнымм магнитным полем Солниа) и несвязанной $c$ солнечными пятнами (связанной $c$ полоидальным магнитным полем Солнща).
\end{abstract}

DOI: 10.31725/0552-5829-2020-153-158

\section{Introduction}

Sun is the main energy source for the climatic system, so variations in solar activity are expected to influence weather and climate. However, the effects are often nonlinear, and solar activity can at some times increase and at other times decrease the values of atmospheric parameters like surface air temperature, circulation indices, etc. [1], and the references therein. This gives rise to doubts about the reality of the Sun-climate relations. A possible explanation can be that in such comparisons the solar activity is usually characterized by the number of sunspots as the parameter with the longest instrumental record. But it only reflects one face of solar activity (toroidal field - related), while the different types of solar activity may have different effects on the atmosphere, and may prevail in different periods.

The driver of solar activity is the solar dynamo which transforms the solar poloidal field in sunspot minimum into toroidal field in sunspot maximum and back. The various geoeffective manifestations of solar activity are related to 
either the poloidal or the toroidal fields: the total and spectral solar irradiance, the solar flares, the coronal mass ejections are related to the solar toroidal field which determines also the number and area of sunspots, so they are all "sunspotrelated", and the sunspot number is a good proxy for them. The slow solar wind, the high speed solar wind streams, and the galactic cosmic rays modulation are related to the solar poloidal field, and are not related to sunspots. The geomagnetic activity, which is the most obvious manifestation of the solar activity influences on the Earth, is due to both "sunspot-related" and "not sunspot-related" solar drivers. Using the method first proposed by Feynman [2], we have separated the inputs of the sunspot-related and not sunspot-related solar activity and, consequently, their relative prevalence $[3,4]$. In Fig. 1 the solid line illustrates the long-term variations of the sunspot-related, and the dashed line of the non sunspot-related solar activity. Both vary cyclically and are in antiphase: the sunspot-related activity prevails in cycles $17-23$, and the nonsunspot related in cycles 10-16.

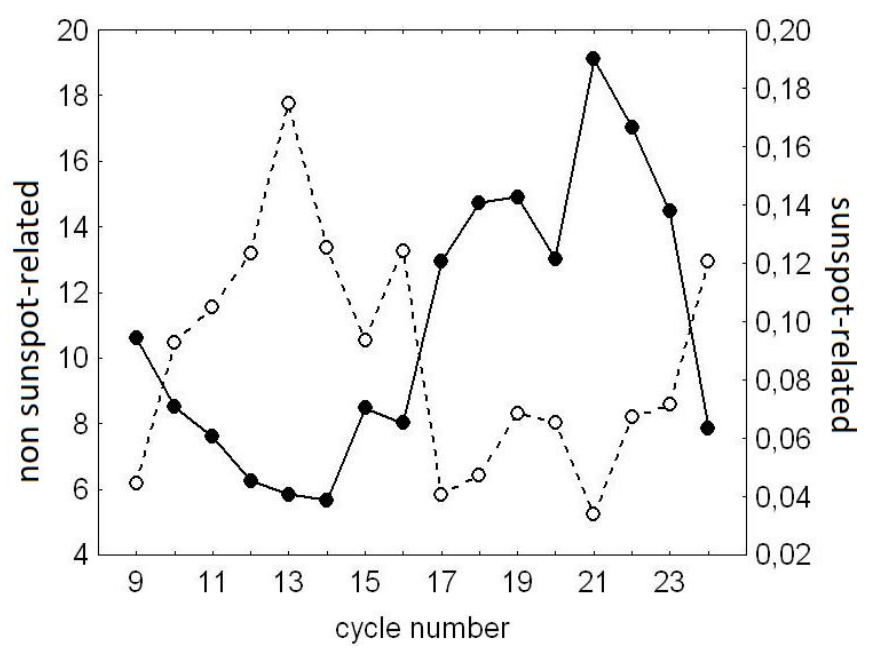

Fig. 1.

\section{Solar activity and surface air temperature}

Different authors have reported positive or negative correlations between solar activity as measured by the sunspot number and the surface air temperature in different meteorological stations and in different periods [1]. Fig. 2 demonstrates the percentage of stations (grey bars) measuring positive (along the positive y-axis) or negative (along the negative y-axis) correlations in the 11year sunspot cycle between solar activity and surface air temperature along with the secular sunspot cycle (solid line). The data are from the stations with long measurement records gathered in the Global Historical Climatology Network (https://www.ncdc.noaa.gov/data-access/land-based-station-data/land-baseddatasets/global-historical-climatology-network-monthly-version-4). It appears that the sign of the correlation depends not on the location but rather on the period studied, and moreover it varies quite regularly: in some periods the 
temperature in the majority of stations rises and in other periods decreases with increasing sunspot number [5].

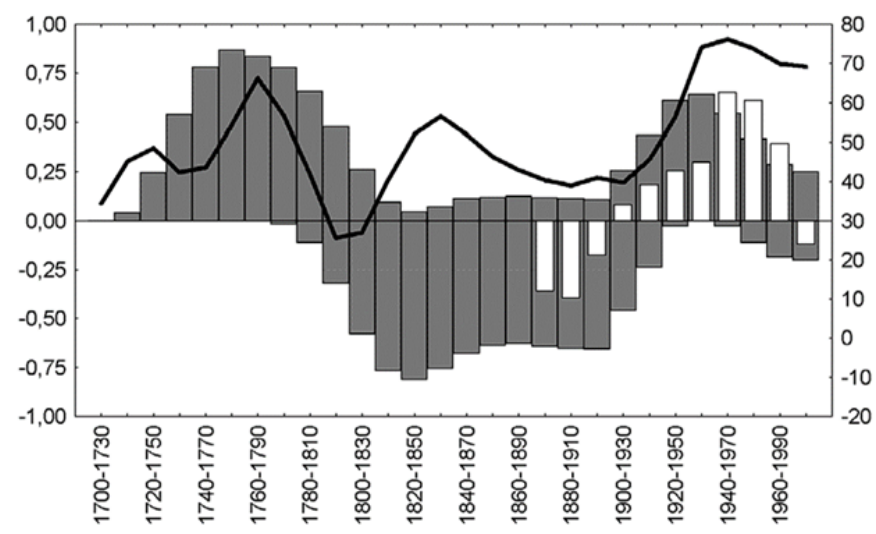

Fig. 2.

We study the change of what solar activity parameters leads to a change in the sign of correlation between solar activity and surface air temperature. Smirnov [6,7] has found that when the Earth passes from one sector of the interplanetary magnetic field into another, the sign of the correlation between the solar wind velocity and the atmospheric parameters changes. The sector boundary crossing means changing the solar hemisphere to which the Earth is exposed. So we could suppose that the activity originating from the two solar hemispheres has different effects upon atmospheric parameters. The white bars in Fig. 2 represent the asymmetry of the solar activity, $A=(\mathrm{SN}-\mathrm{SS}) /(\mathrm{SN}+\mathrm{SS})$ where SN and SS stand for the total sunspot area in the Northern and Southern solar hemispheres, respectively. Negative A seen in the $19^{\text {th }}$ century means more active Southern solar hemisphere and is associated with negative correlation between solar activity and surface air temperature in the 11-year cycle, and positive $\mathrm{A}$ in the $20^{\text {th }}$ century - more active Northern hemisphere and positive correlation. We can therefore suggest that solar asymmetry is a parameter which changes in consecutive secular cycles, being positive in "even" cycles (if we denote the 20 th century secular cycle as even) and negative in odd ones.

\section{Solar activity and the North Atlantic Oscillation}

The variations in weather and climate are related to variations in atmospheric circulation - the system of atmospheric motions over a certain region with its specific features (local circulation) or on the scale of the whole globe (general atmospheric circulation). The North Atlantic Oscillation (NAO) is a north-south seesaw oscillation in atmospheric mass between the low pressure center of action near Iceland (Iceland Low) and the high pressure center of action in subtropical Atlantic (Aleutian High) which exerts a dominant influence on wintertime temperatures across much of the Northern Hemisphere. During winter months, NAO variability explains about one-third of the Northern 
Hemisphere interannual surface temperature variance [8]. NAO positive phase, when the pressure in Iceland Low is even lower than normal, and the pressure in Aleutian High is even higher than normal, is associated with strong midlatitude westerly winds across the Atlantic onto Europe. The westerlies move relatively warm and moist maritime air over much of Eurasia, while stronger northerlies over Greenland and northeastern Canada carry cold air southward. The situation changes to the opposite in the NAO negative phase when both centers of action are weaker: the pressure is higher than average in Iceland Low, and lower than average in Azores High, as a result the westerly winds get weaker and positioned further south, and the temperature patterns are opposite.

In an earlier study [7] we showed that the correlation between solar activity and the NAO index changes systematically (Fig.3), and related the sign of the correlation to the solar activity asymmetry: when the northern solar hemisphere is more active, the correlation is negative, and when more active is the southern solar hemisphere, the correlation is negative. The vertical lines separate the periods of positive and negative correlations. (These periods were chosen in such a way as to give the highest positive or negative correlation between NAO and solar activity, so they are somewhat arbitrary). In the $20^{\text {th }}$ century the correlation is negative, but in the $19^{\text {th }}$ century it is positive, negative again in the $18^{\text {th }}$ century, and positive again in the $17^{\text {th }}$ century. The correlation in the earliest period is not statistically significant, but it should be noted that this is the period of the Maunder minimum when sunspot activity was atypical. The change in the correlation between the long-term variations of NAO and solar activity coincides with the change in the correlation between surface air temperature and solar activity in the 11-year sunspot cycle, which as noted above, is supposed to coincide with the changes in the long-term solar activity asymmetry. We can, therefore, speculate that when the southern solar hemisphere is more active, increasing solar activity in the secular solar cycle leads to strengthening of the zonal atmospheric circulation, and when the northern solar hemisphere is more active, increasing solar activity in the secular solar cycle leads to weakening of the zonal circulation.

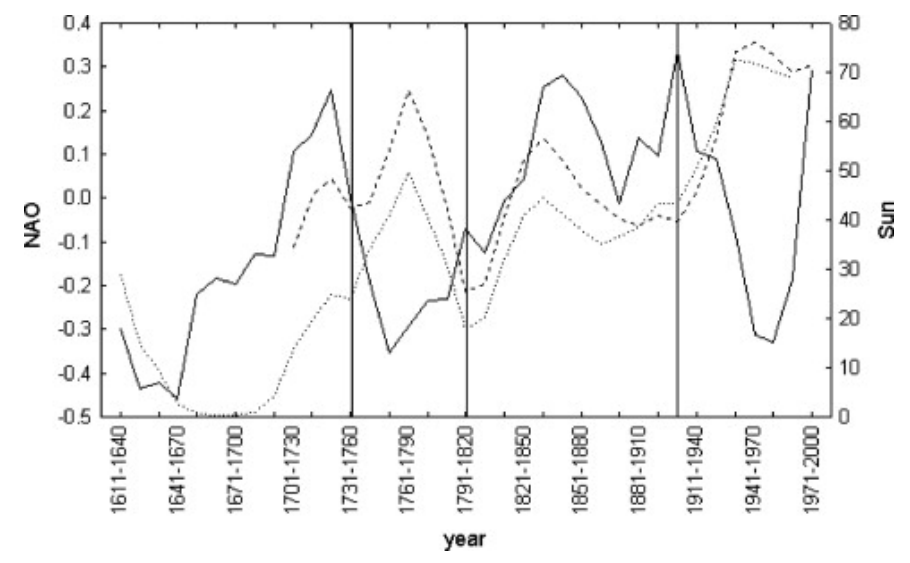

Fig. 3. 
In a following study [8] we investigated the influence of sunspot-related and non sunspot-related solar activity drivers on the atmospheric circulation as quantified by the Northern Annular Mode (NAM) index. NAM is defined as the difference in atmospheric pressure between high (above $60^{\circ}$ ) and middle (around $45^{\circ}$ ) northern latitudes at pressure levels from $1000 \mathrm{hPa}$ (surface) to $10 \mathrm{hPa}$ (about $32 \mathrm{~km}$ ), and NAO is its surface manifestation. We used NAM index as it provides information about the vertical structure and allows evaluating the influences at different levels. To separate the influence of the two types of solar drivers, we have divided the data for periods with high geomagnetic activity and low solar irradiance when non sunspot-related solar activity predominates, and periods with low geomagnetic activity and high solar irradiance when sunspotrelated activity predominates. We found that solar non sunspot-related activity increases the NAM index at all levels, while sunspot-related activity decreases it. This is a possible explanation of the changing correlation between the North Atlantic Oscillation and solar activity.

\section{Atmospheric circulation and temperatures in Europe}

Hess and Brezowsky [9] identified a number of circulation patterns in Europe and produced a catalog of the prevalence of the various forms in the period 1881-1998. To further study the influence of solar activity on the atmospheric circulation and surface air temperature, Fig.4 presents the correlation between the non sunspot-related geomagnetic activity and the prevalence of circulation forms leading to higher than average temperatures in Europe (South-Westerly cyclonic and anticyclonic), upper panel, and the circulation forms leading to lower than average temperatures (North-Westerly cyclonic and anticyclonic), lower panel. With increasing geomagnetic activity in the last century, the frequency and persistence of forms of circulation leading to higher than average temperatures increases, while the frequency and persistence of forms of circulation leading to lower than average temperatures decreases.

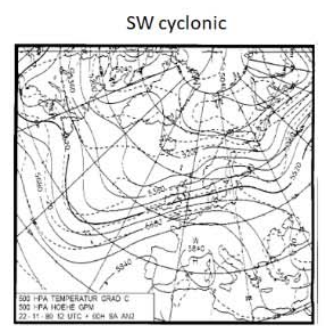

NW cyclonic

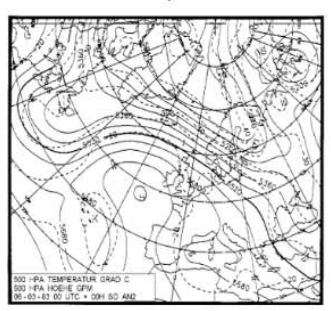

SW anticyclonic

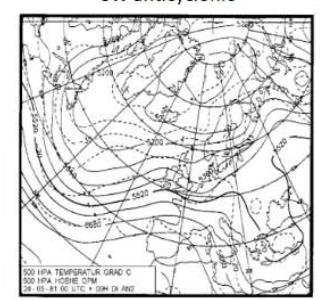

NW anticyclonic

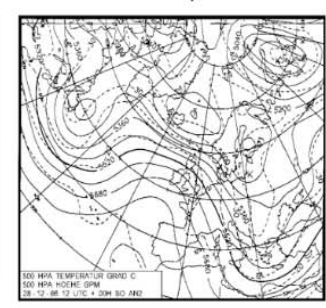

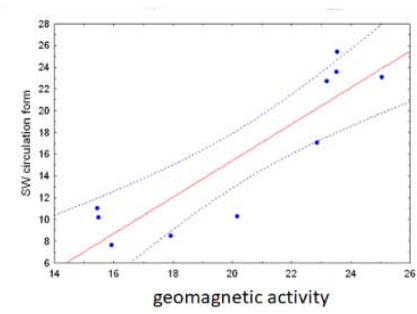
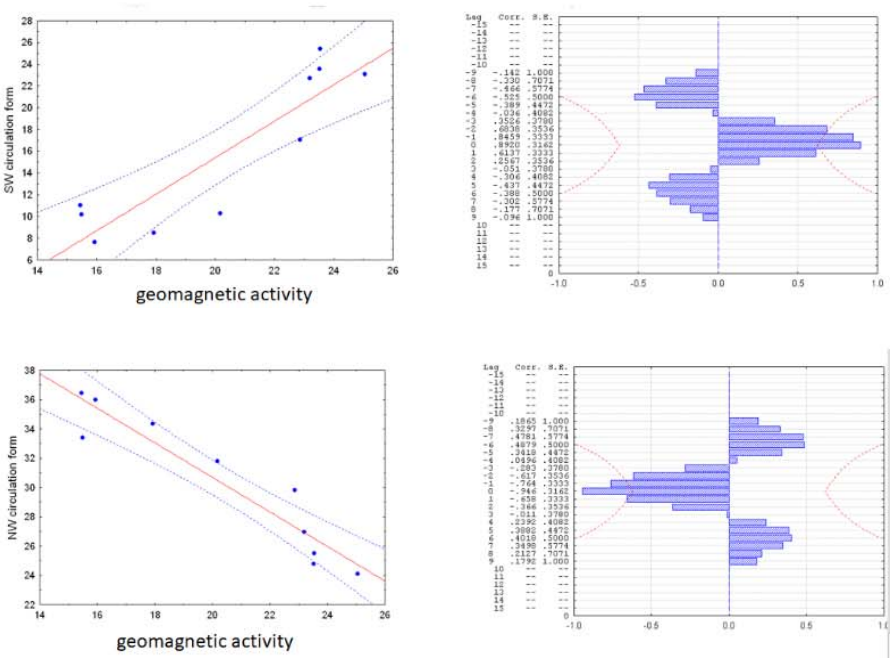

Fig. 4. 
These results demonstrate that the periods when the correlation between the surface air temperature and sunspot number and between the North Atlantic Oscillation and the sunspot number change coincide with the periods when the prevalence of sunspot-related and non sunspot-related solar activity changes.

\section{Summary}

Both meteorological parameters like surface air temperature, and largescale atmospheric circulation patterns orchestrating hemispheric and global climate like the North Atlantic Oscillation, undergo long-term variations closely related to the secular solar activity variations. The influence of solar activity on meteorological parameters is supposed to be mediated by the influence of solar activity on the atmospheric circulation patterns. The correlations between solar activity and both the indices of atmospheric circulation and surface air temperature are found to change sign systematically, depending on either the north-south solar activity asymmetry, of the relative prevalence of sunspot-related and non sunspot-related solar drivers, or both. The identification of the causes of these changing correlations requires further studies.

\section{Acknowledgements}

This study is partly supported by the National Science Fund of Bulgaria, Contract KP-06-N34/1 "Natural and anthropogenic factors of climate change analyzes of global and local periodical components and long-term forecasts".

\section{References}

1. Herman J.R., Goldberg R.A. // Sun, Weather and Climate. NASA, Washington, DC, 1978.

2. Feynman, J. // Journal of Geophysical Research. 1982. V. 87. P. 6153.

3. Kirov B. et al. // Geomagnetism and Aeronomy. 2013. V. 53. P. 813.

4. Kirov B. et al. // Geomagnetism and Aeronomy. 2015. V. 55. P. 1033.

5. Georgieva K., Kirov B. // Bulgarian Journal of Physics. 2000. V. 27. P. 28.

6. Смирнов Р.В. // Докл. АН СССР. 1967. Т. 175. С. 76.

7. Смирнов Р.В. // Докл. АН СССР. 1969. Т. 180. С. 88.

8. Hurrell J.W. et al. // Science. 2001. V. 291. P. 603.

7. Georgieva K. et al. // Advances in Space Research. 2007. V. 40. P. 1152.

8. Georgieva K. et al. // J. of Atmospheric and Solar-Terrestrial Physics. 2012. V. 90. P. 15.

9. Hess P., Brezowsky H. // Catalog der Großwetterlagen Europas (1881-1998), 1999. Gerstengarbe and Werner. 